\title{
Information processing in info-communication media of geodynamic monitoring on the basis of adaptive queuing system
}

\author{
Kuzichkin O. R. ${ }^{1}$, Eremenko V.T. ${ }^{2}$, Loginov I. V. ${ }^{3}$, Grecheneva A. V. ${ }^{4}$, \\ Eremenko A. V.5, Dorofeev N. V. ${ }^{6}$ \\ ${ }^{1,4}$ Belgorod State University, Russia \\ ${ }^{2,3,5}$ Orel State University, Russia \\ ${ }^{6}$ Vladimir State University, Russia
}

\begin{tabular}{l}
\hline \hline Article Info \\
\hline Article history: \\
Received Aug 21, 2019 \\
Revised Nov 15, 2019 \\
Accepted Feb 24, 2020 \\
\hline
\end{tabular}

\section{Keywords:}

Adaptive control

Controlled QS

Geodynamic monitoring

Info-communication

environment

Modeling

Service intensity

\begin{abstract}
The paper considers the problem of modeling the processing of geodynamic information in a reconfigurable information-communication environment of geodynamic monitoring based on an adaptive queuing system. It was established that due to the complexity and diversity of geodynamic information, the number of geodynamic control points is expanding and the number of controlled parameters, the number of controlled objects of natural-technical systems (NTS) are increasing. This leads to an increase in the overall load on the info-communication monitoring environment, an increase in the processing time and the response time of the NTS geodynamic stability control system to negative changes. This leads to the need for adaptive optimization of the info-communication environment of geodynamic monitoring. The model of a composite stream describing the change in the nature of the tasks performed by geodynamic monitoring was determined, approaches to reconfiguration management based on minimization of the loss functional were proposed. The constructed model of the process of functioning and the analytical dependencies obtained for it allow analyzing the process of processing geodynamic information in info-communication environments to optimize the mechanisms of their functioning.
\end{abstract}

This is an open access article under the $\underline{C C B Y-S A}$ license.

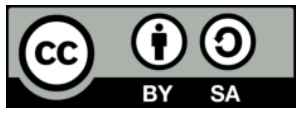

\section{Corresponding Author:}

Kuzichkin O. R,

Belgorod State University, 85 Pobedy St, Belgorod, Russia.

Email: bakhteeyar@gmail.com

\section{INTRODUCTION}

At present, geotechnical and geodynamic monitoring systems are used to solve problems of protecting life-supporting and man-made objects from possible catastrophic scenarios, as well as monitoring the bearing capacity of soils during the life cycle of objects and natural-technical systems (NTS) [1-3]. It allows an assessment of geomechanical changes in the geological environment, as well as technological control of buildings and structures in order to form a predictive estimate of the possibility of man-made disasters. The complexity and diversity of the manifestation of geodynamics of environments leads to the need to expand the number of controlled parameters of geodynamic objects in the organization of monitoring, which significantly increases the flow of measurement information. One of the main problems of conducting automated geodynamic studies is that when solving problems of geodynamic control, 
it is necessary to significantly reduce the information processing time to form an operational response to critical changes of the object of study. It is the improvement of quality indicators, reduction of research time and, accordingly, increase in the efficiency of geodynamic control is the main goal of the development and application of automated systems of geodynamic research [4].

It is obvious that the processing in the info-communication environments of geodynamic monitoring has a stochastic nature due to the random nature of the receipt of data on the presence of complex geodynamic changes in the NTS and its processing. For the analysis of such systems involving the processing of info-communication flows of geodynamic data (requests), queuing theory models are used. In the conditions of the need to localize the source and the possible consequences of geodynamic changes in the situation in the NTS, an operational restructuring of the in put task flow is necessary and for its processing the info-communication environment reconfiguration process is implemented. At the same time, in conditions of distributed collection and processing centers made for the functioning of the integrated services of the geodynamic monitoring system, there is a high significance of changing system requirements. In the existing models of processing applications in info-communication systems this is not fully taken into account.

Regional geodynamic monitoring systems are characterized by the presence of large-scale geodynamic information processing centers with a high-performance info-communication environment serving as the basic infrastructure. The management and adaptation of such info-communication media that are dynamically changed for the tasks to be solved is an urgent task widely considered in the literature [5-7]. The main technological problem of managing an info-communication environment is the improvement of the basic properties of adaptive info-communication environments-the self-configuration, the self-service, the self-optimization, the fault tolerance (self-defense) under conditions of structural and functional heterogeneity and changes in operating conditions [7, 8]. Also in [8], the problem of substantiating the composition, structure, quantitative and qualitative characteristics of information necessary for effective management is highlighted.

Known approaches to managing the reconfiguration of info-communication environments focus on improving the methodologies for justifying development strategies and developing reconfiguration methods for industry-specific features. Widely used are approaches to taking into account goal setting in upgrading info-communication environments [7], technical and economic analysis of development options [9]. Solving the problem of optimal reconfiguration of information and communication media in changing conditions is associated with the development of methods for the structural and functional adaptation of control objects. Recently, general theoretical principles of the work and analysis of information and communication media of adaptive information collection and processing systems have been developed. In [10], approaches are proposed for solving the problem of planning structural and functional reconfiguration of complex objects in order to increase the reliability and survivability of complex systems in dynamically changing conditions. The tools for reconfiguration management for hardware with increasing the efficiency of the reconfiguration process are considered in [11]. In [12], a method of active management of complex objects was proposed, which presupposes model-algorithmic descriptions of processes, a semantic interpretation of standard and non-standard states and the formation of control objects with integral estimates of states based on them. In [13], questions of scenario control of complex organizational and technical systems were considered at the expense of solving the problem of optimum par value with a continuous utility function to select the best impulse control process.

However, for distributed systems for collecting and processing heterogeneous information of geodynamic monitoring, it is necessary to solve the problem of developing a model for processing geodynamic information in the info-communication environment of a geodynamic monitoring center. This model is based on a controlled queuing system in the face of changing system requirements determined by the operational geodynamic situation in the NTS.

\section{METHODOLOGY}

The organizing of the geodynamic monitoring of the NTS assumes the division of monitoring objects into local geographically distributed areas. The construction of NTS control systems is reduced to the analys is of local observations of separate geodynamically active zones [14-16]. As practice shows, some areas of the NTS have their own rhythm and different geodynamic sensitivity to disturbing factors, due to natural conditions and the level of technogenesis [17]. Possessing its own distinctive characteristics and parameters, separate areas of the NTS are represented as separate geodynamic objects that can be classified and separated from a set of geodynamic models. Each such object has an impact on specific processes occurring in the NTS. This allows to obtain generalized estimates of geodynamic changes and predict their further development and impact on the sustainability of the PTS based on the registration and analysis 
of changes in the activity of geodynamically active zones. The intensity of changes in geodynamically active zones can significantly exceed the intensity of background geodynamic changes, which allows predicting the occurrence of adverse factors in the NTS in advance [18].

The activity of geodynamic zones is characterized by complexity and diversity, which makes it necessary to expand the number of control points and increase the number of controlled parameters, the number of controlled objects of the NTS. The expansion of the network of data collection significantly increases the amount of useful and control information, increases the load on communication channels, intermediate equipment and data processing devices. This entails an increase in the total load on the info-communication monitoring environment, an increase in data processing time and response time of the NTS geodynamic stability control systemto negative changes [19].

Figure 1 shows the structure of the geodynamic monitoring system of the regional NTS. It consists of several local-level NTSs, which include several local geodynamic control NTSs. At the local level, measuring systems register the values of monitored parameters determined for each area separately.

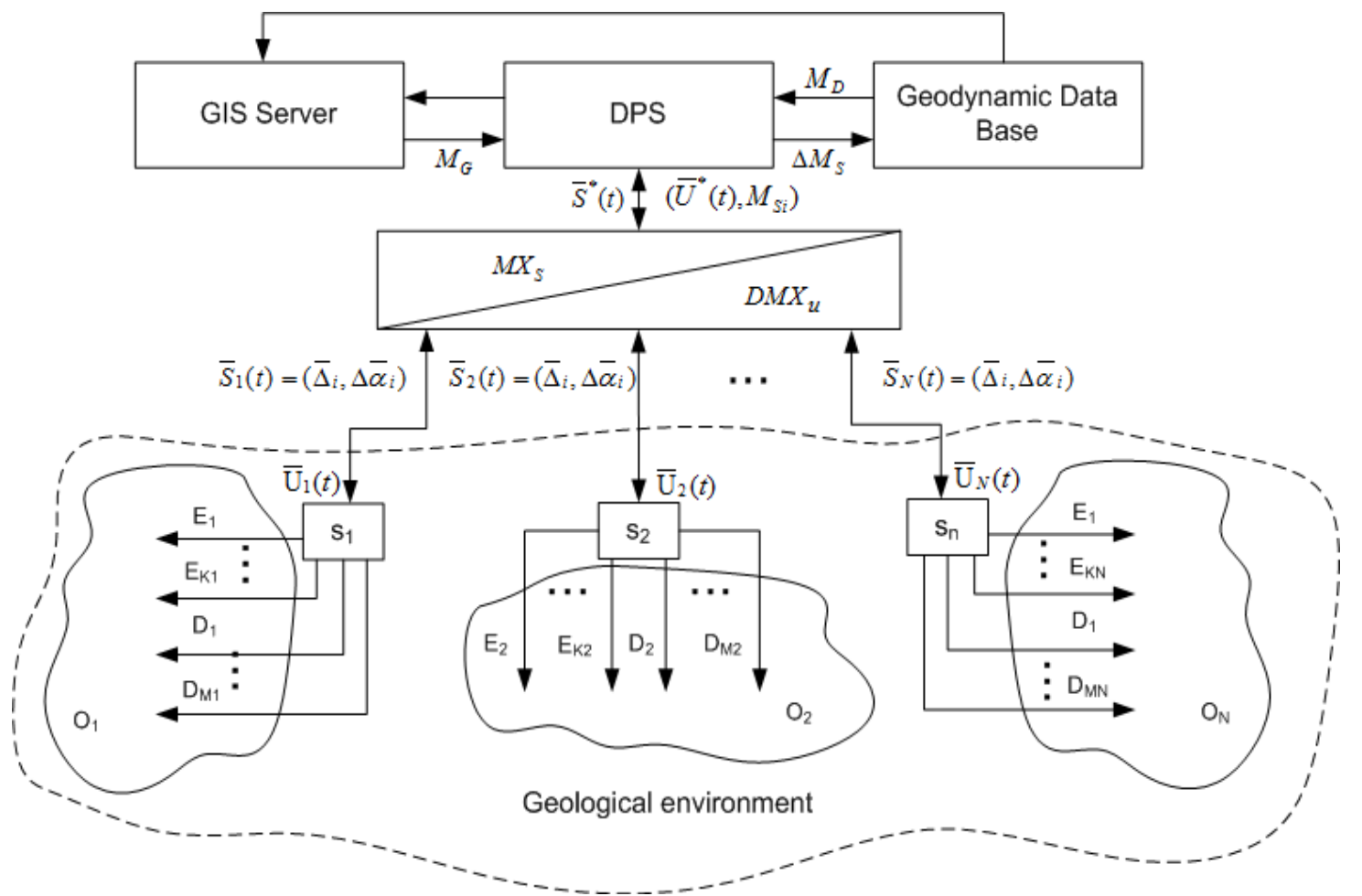

Figure 1. The structure of the geodynamic monitoring system

The processes of information processing at the points of geodynamic control Oi are constructed in accordance with the basic principles of solving the inverse problem of geodynamic control [20]:

$$
\left(\mathbf{M}_{S i}, \Delta \bar{\alpha}_{i}, \mathbf{E}_{i}\right)=\mathbf{A}^{-\mathbf{1}}\left(\mathbf{D}_{i}\right)
$$

where Di is the observed data vector; are the parameters of the sources of the probe field, determined by the specified model and control signal; A-1 is the inverse problem operator.

The purpose and principle of operation of the virtual multiplexer (MXS,DMXU,) is to match the flows of geodynamic data $\bar{S}^{*}=\left(\left(\bar{\Delta}_{i}, \Delta \bar{\alpha}_{i}\right) i=\overline{1}, \bar{N}\right)$ and control signals of the system of spatial-temporal processing of data of the geodynamic control with the processing unit (DPS). The algorithms of the virtual multiplexer are built on the principles of its dynamic restructuring and adaptation to geodynamic variations in the NTS with the purpose of increasing the sensitivity of the system to pre-crisis situations. In this case, consideration of the work of the system for collecting and processing geodynamic data in the monitoring system can be carried out on the basis of the QS with the reconfiguration of the info-communication environment.

Information processing in info-communication media of geodynamic monitoring on the ... (Kuzichkin O.R) 


\section{RESULTS}

Adaptation of the info-communication environment of the geodynamic monitoring system solves the problems of fine tuning the system for controlled objects and optimizing the performance of geodynamic information processing. In the work, we will limit ourselves to the possibility of changing the productivity of at one moment of time only for one type of tasks. Taking into account the presented assumptions, the modernization system can be represented as a closed QS, in which the processed requests for the adaptation of the info-communication environment do not leave the system, but return to the queue.

For performance control, various service disciplines can be applied:

a) Implementation the choice from the queue of the next application in one way or another, for example, FCFS, FCLS, SIRO;

b) Implementation the ordering of requests according to some of their particular characteristics, for example, by the number of requests of the corresponding type that came to the info-communication environment during the last reconfiguration cycle;

c) Implementation the solution of optimization problems for controlled Markov chains using dynamic programming or the Howard method [21-25] for various complex risk functions.

In the general case, the third class of service disciplines allows finding optimal solutions for the case of the observed process of processing requests in the system, however, it requires compiling and solving optimization equations based on differential equations for linking the price change with the optimal strategies:

$$
-\frac{d \Phi_{t}(x)}{d t}=\min _{u \in U_{x}}\left[l_{x}(u)+\sum_{y \in X} a_{x y}(u) \Phi_{t}(y)\right]
$$

The reconfiguration time in the general case is distributed according to some law with intensity (productivity). Without reducing the generality of the conclusions, the exponential law can be considered as the law of the distribution of the duration of reconfiguration. The productivity of the reconfiguration service device decreases depending on the stage of reconfiguration. As a function of decreasing the performance of reconfiguration, a power function can be considered:

$$
\frac{1}{\mu_{j, k}}=\frac{\kappa_{j}}{\mu_{j, k-1}}=\frac{\kappa_{j}^{k}}{\mu_{j, 0}}
$$

where is the service productivity of the -th task flow after the -th reconfiguration stage; is the coefficient of productivity decline; is the productivity of the flow service at the initial time. Figure 2 shows the graphs of modeling the change in the average service time for controlled (a) and random (b) selection of the type of stream for upgrading the productivity of processing geodynamic information.

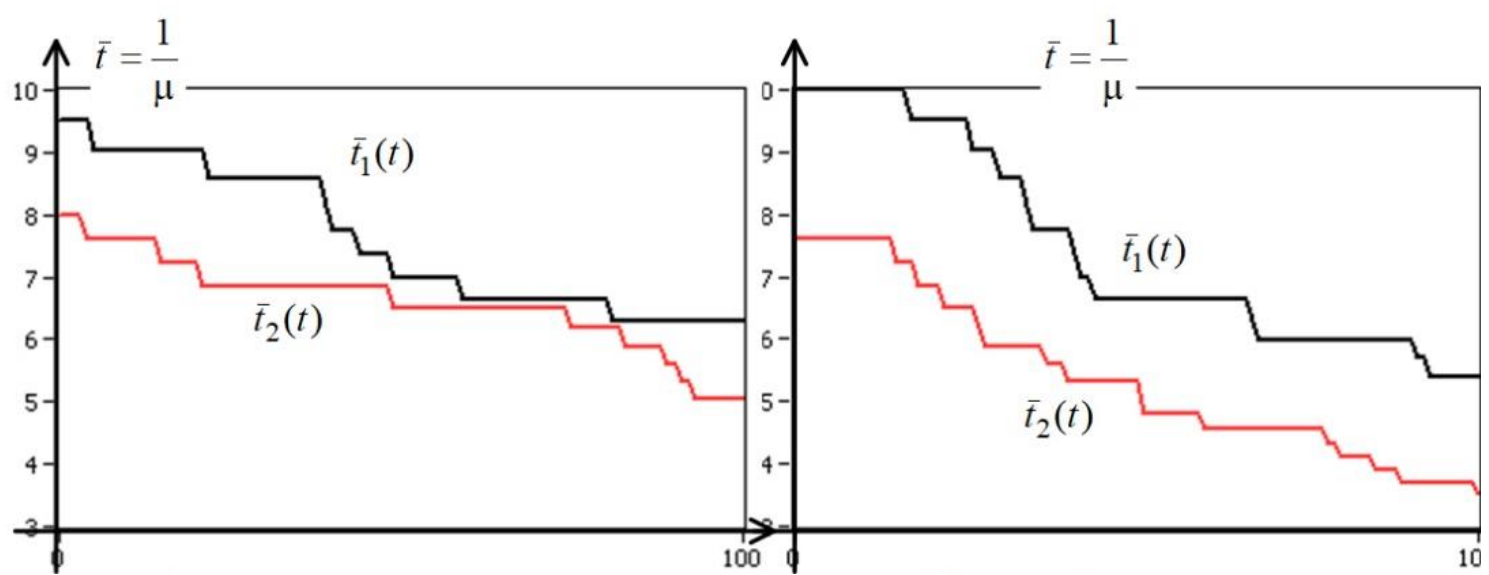

(a)

(b)

Figure 2. The graphs of changes in the productivity of the info-communication environment by types of requests, (a) Controlled productivity change, (b) Random productivity change 
Analysis of the process of the geodynamic information processing in adaptable info-communication environments based on controlled QS The info-communication environment of the geodynamic monitoring center is present in the form of a controlled single-channel QS type $M / M / 1 /$, where the control is implemented by increasing the processing productivity of tasks of the same type:

$$
\mu_{j, k}=\mu_{j, k-1}+\Delta \mu_{j} \kappa_{j}
$$

The source data for modeling the input task stream:

$$
\begin{aligned}
& \Lambda=\lambda_{1}+\lambda_{2} \\
& \operatorname{param}_{1}=\left\langle\left(i n c_{1, \text { max }}, T_{1}, T_{1, \text { нач }}, \eta_{\text {нач }}, \eta_{\text {ок }}\right), g(i n c, t)=\left\{\begin{array}{c}
i n c_{1}(t) \times e^{-i n c_{1}(t) t}, t \geq 0 \\
0, t<0
\end{array}\right\rangle\right. \\
& \operatorname{param}_{2}=\left\langle\left(i n c_{2, \text { max }}, T_{2}, T_{2, \text { нач }}, \eta_{\text {нач }}, \eta_{\text {ок }}\right), g(i n c, t)=\left\{\begin{array}{c}
i n c_{2}(t) \times e^{-i n c_{2}(t) t}, t \geq 0 \\
0, t<0
\end{array}\right\rangle\right. \\
& q w_{1}=\left\langle\text { type }={ }^{\prime} 1^{\prime}, r_{1}, \xi_{1}(t)=\left\langle b_{1}, T_{1, \text { max }}\right\rangle\right\rangle \\
& q w_{2}=\left\langle\text { type }=2^{\prime}, r_{2}, \xi_{2}(t)=\left\langle b_{2}, T_{2, \text { max }}\right\rangle\right\rangle
\end{aligned}
$$

where the values of the parameters of the effect $b_{1}, T_{1, \max }, b_{2}, T_{2 \text {,max }}$ are distributed according to a uniform distribution law with the following parameters: $b_{1} \in[5 ; 15] ; \quad T_{1, \max } \in[50 ; 150] ; \quad b_{2} \in[7,5 ; 22,5]$; $T_{2, \max } \in[50 ; 150]$.

Figure 3 shows the graphs of changes in the intensity of the receipt of tasks in the info-communication environment of the geodynamic information processing center for the total flow and each flow separately: a) envelope of the intensity of the receipt of tasks; b) instantaneous intensity value.

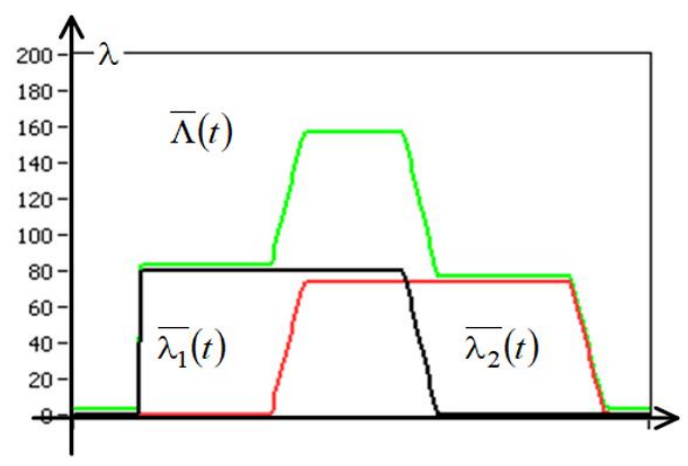

(a)

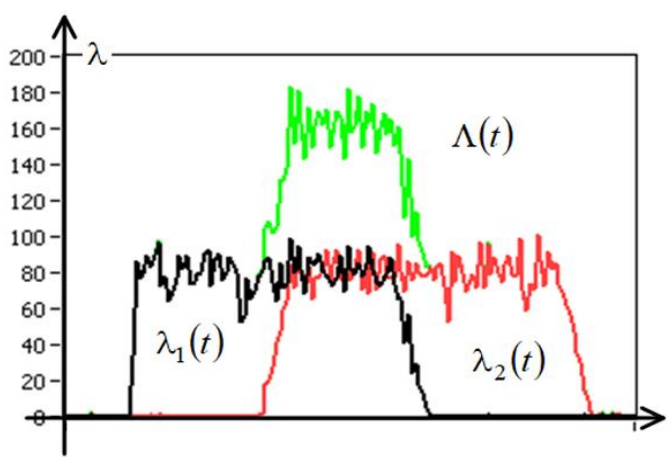

(b)

Figure 3. The graphs of the change in the intensity of the flow of geodynamic information (queries)

(a) Intensity envelope, (b) Instant intensity value

Control of QS is implemented on the final time interval. In work two disciplines of controlling of the productivity of QS (the info-communication environment) are considered:

a) SIRO (in random order);

b) According to the maximum of accepted tasks for the planning period:

$$
R_{t}^{T}[x, u ; \delta]=\mathrm{M}^{\delta}\left\{L_{[s, t)} / x_{t}, u_{t}\right\}=\max _{n_{i} \in N} n
$$

where is the number of tasks of a given type received at the system input.

Information processing in info-communication media of geodynamic monitoring on the... (Kuzichkin O.R) 
Figure 4 presents graphs of change in the intensity of service tasks by the type from the time (a) In random order, (b) With use of the loss functional. Figure 5 shows graphs of changes in relative throughput $\rho(t)$ and $\bar{\rho}(t)$, as well as the queue size for the simulated state:

$$
\rho(t)=\frac{\Lambda(t)}{\bar{\mu}(t)}, \bar{\rho}(t)=\frac{\bar{\Lambda}(t)}{\bar{\mu}(t)}
$$

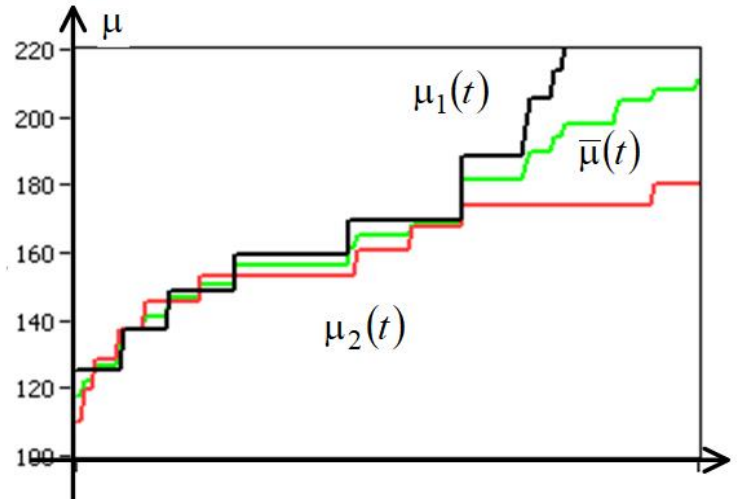

(a)

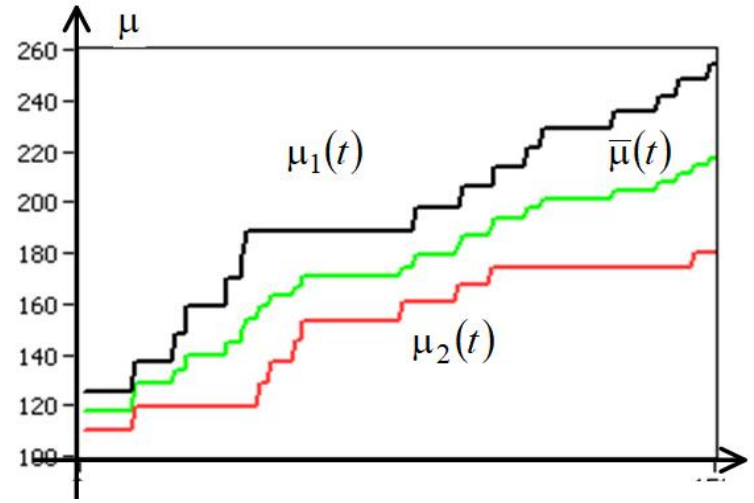

(b)

Figure 4. The graphs of the change in the intensity of service tasks by the type from the time (a) In random order, (b) With use of the loss functional

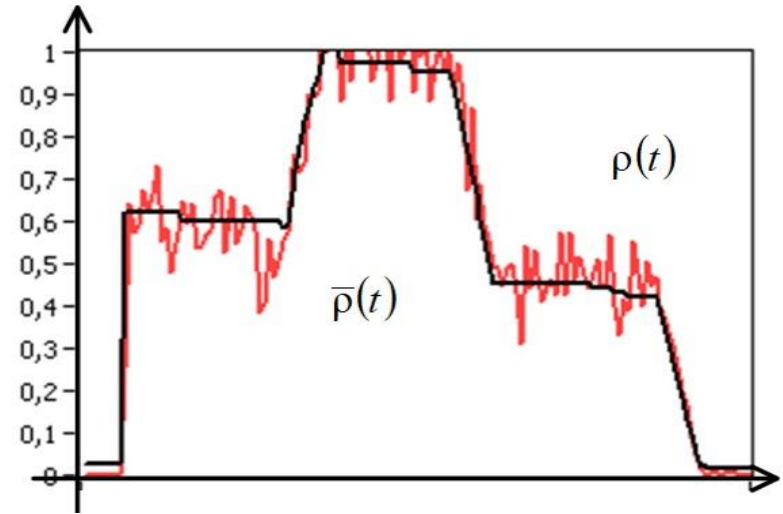

(a)

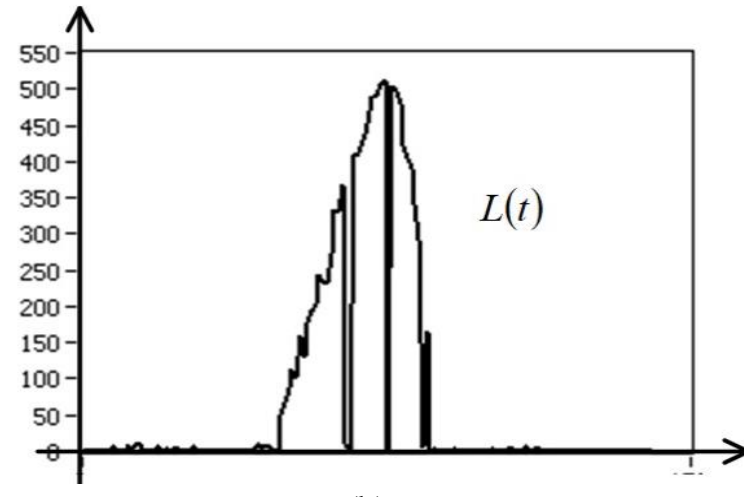

(b)

Figure 5. The Graphs of changes in relative bandwidth and queue size from the time (a) The relative bandwidth, (b) The queue size

In this work, two disciplines of servicing a geodynamic monitoring center(Figure 6) are investigated:

a) FCFS (first come - first served);

b) FCLS (first come - last served).

Comparison of results performed by the magnitude of the effect: $E=\sum_{i=0}^{N} \xi_{i}\left(t_{i}\right)$

where $\xi_{i}\left(t_{i}\right)$ is the magnitude of the effect of processing the $\mathrm{i}$-th request, is the number of requests processed during the planning period. 


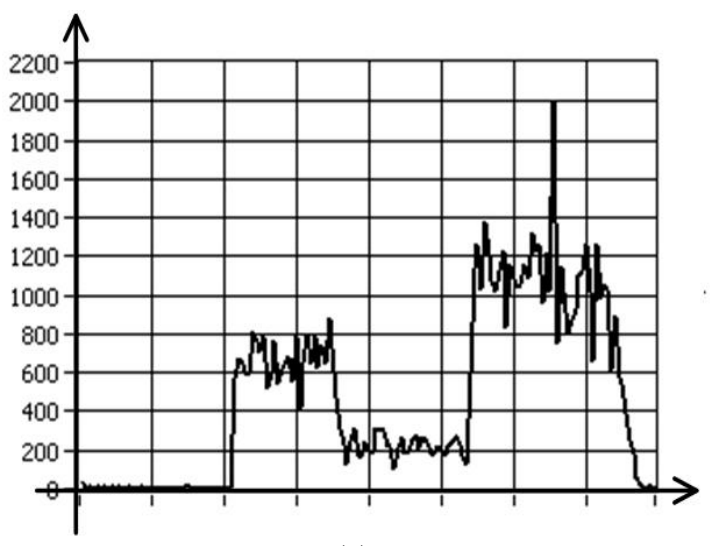

(a)

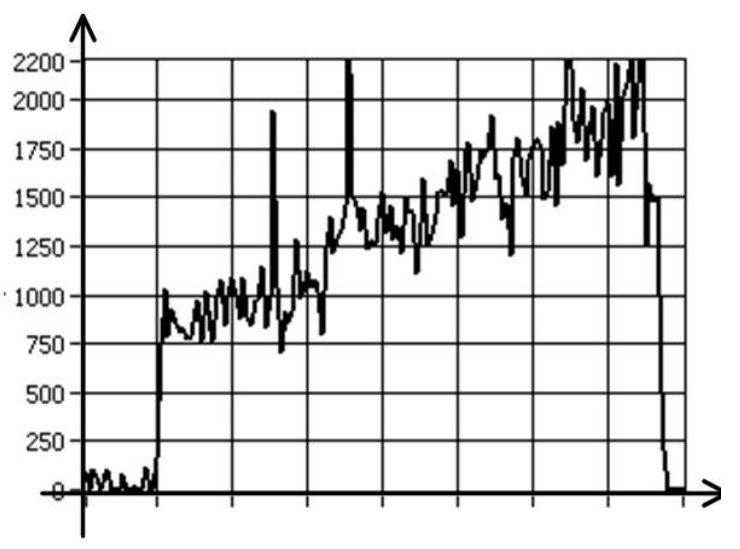

(b)

Figure 6. The graphs of changes in the effect of processing tasks in the QS from the time, (a) Discipline FCFS, (b) Discipline FCLS

\section{CONCLUSION}

The paper was proposed an approach to modeling and analyzing the processing of geodynamic information in a reconfigurable info-communication environment based on a controlled queuing system. A composite flow model was defined that describes the change in the nature of the tasks performed at the center of geodynamic monitoring, and approaches to reconfiguration management were proposed based on minimizing the loss functional in the final segment. The constructed model of the process of functioning and the analytical dependencies obtained for it allow analyzing the process of processing geodynamic information in info-communication environments to optimize the mechanisms of their functioning.

The results show that a change in the service discipline significantly changes the effect of geodynamic information processing in the QS. A change in performance management strategy also makes it possible to achieve a significant reduction in the geodynamic risk functional in the NTS. The direction of further research is the creation of a service discipline based on solving optimization problems (FMT), building optimal performance management schemes, modeling multi-channel QS for analyzing information collection and processing processes in decentralized geodynamic monitoring systems.

\section{REFERENCE}

[1] J. Zhang and L. Tian, "Study on Countermeasures of Mine Geo-environmental Comprehensive Treatment for Mining-city," Urban Geology, vol. 3, 2010.

[2] Q. Zheng, et al., "Genesis and Evolution of Kongshan Baiyun Karst Cave in Lincheng County, Hebei Province," Advances in Earth Science, vol. 28, pp. 86-93, 2013.

[3] M. Labbate, et al., "Anthropogenic impacts on the microbial ecology and function of aquatic environments," Frontiers in microbiology, vol. 7, pp. 1044, 2006.

[4] V.A. Korolev, "Monitoring of the geological environment," M.: MGU, 1995.

[5] A. Tylecote, and F. Visintin, "Corporate governance, finance and the technological advantage of nations," Routledge, 2007.

[6] B.V. Sokolov, et al., "Influence analysis of informatics and computer science on development of theory and sy stems of control by complex objects," Trudy SPIIRAN, vol. 11, pp. 11-51, 2009.

[7] N.P. Sidorov, "Methods and tools for modeling the IT infrastructure of an enterprise // Questions of regional economics," vol. 3, pp. 81-90,2010.

[8] L. Wills, et al., "An open software infrastructure for reconfigurable control systems," In Proceedings of the 2000 American Control Conference, ACC, vol. 4, pp. 2799-2803, Jun 2000.

[9] Leiras A, et al., "Literature review of humanitarian logistics research: trends and challenges," Journal of Humanitarian Logistics and Supply Chain Management, vol. 4, pp. 95-130, May 2014.

[10] B. V. Sokolov, et al., "Principles, models, methods, and algorithms for the structure dy namics control in complex technical systems," In International Conference on Computational Science and Its Applications, Springer, Berlin, Heidelberg, pp.407-416, May 2005.

[11] M. Platzner, et al., "Dynamically Reconfigurable Systems: Architectures, Design Methods and Applications," Springer Science \& Business Media, Mar 2010.

[12] B. V. Sokolov, et al., "Theoretical and technological foundations of complex objects proactive monitoring management and control," In Proceedings of the Symposium Automated Systems and Technologies Peter the Great, St. Petersburg Poly technic University, Leibniz Universität Hannover, pp. 103-110, 2015. 
[13] N. Sadovnikova, et al., "Scenario forecasting of sustainable urban development based on cognitive model," In Proceedings of the IADIS International Conference ICT, Society and Human Beings, pp. 115-119, Jul 2013.

[14] R. V. Sharapov and O. R. Kuzichkin, "Geodynamic monitoring in area of nuclear power plant," In Applied Mechanics and Materials, vol. 492, pp. 556-560, 2014.

[15] R. V. Sharapov and O. R. Kuzichkin, "Monitoring of karst-suffusion formation in area of nuclear power plant," 2013 IEEE 7th International Conference on Intelligent Data Acquisition and Advanced Computing Systems (IDAACS), Berlinpp, pp. 810-813, 2013.

[16] V. T. Trofimov, "The ecological-geological system, its types and position in the structure of an ecosystem," Moscow University Geology Bulletin, vol. 64, pp. 111-115, Apr 2009.

[17] O. Kuzichkin, et al., "Selection and Justification of The Location of the Network of Points of Stationary Observations in the Local Zones of Karstological Monitoring," International Multidisciplinary Scientific GeoConference: SGEM: Surveying Geology \& mining Ecology Management, vol. 18, pp. 629-36, 2018.

[18] A. Grecheneva, et al., "Information and Analytical Support for the Processing of Heterogeneous Data of Geotechnical Monitoring," International Multidisciplinary Scientific GeoConference: SGEM: Surveying Geology \& mining Ecology Management, vol. 17, pp.453-60, 2017.

[19] N.V. Dorofeev and O.R. Kuzichkin, "Processing of heterogeneous data in GIAS of Geodynamic Monitoring," The 8th International Conference on Intelligent Data Acquisition and Advanced Computing Systems, pp. 33-37, Sep 2015.

[20] P. K. Zeitler, et al., "Erosion, Himalay an geodynamics, and the geomorphology of metamorphism," GSA Today, vol. 11, pp. 4-9, Jan 2001.

[21] V. V. Rykov, "Managed queuing systems // Theory of probability," Mathematical statistics. Theoretical cybernetics, vol. 12, pp.43-153,1975.

[22] H. Pape, "Development of a standard for transient measurement of junction-to-case thermal resistance," Microelectron, Reliab, vol. 52, pp. 1272-1278, 2012.

[23] V. Székely and A. Szalai, "Measurement of the time-constant spectrum: Sys-tematic errors, correction," Microelectron, vol. 43, pp.904-907, 2012.

[24] H. Morkoç, et al., "Polarization effects in nitride semiconductor device structures and performance of modulation doped field effect transistors," Solid-State Electronics, vol. 43, pp. 1909-27, 1999.

[25] V. Szekely, "Identification of Networks by Deconvolution: Chances and Limits," IEEE Trans, CIRCUITS Syst, vol. 45, pp. 15, 1998.

\section{BIOGRAPHIES OF AUTHORS}

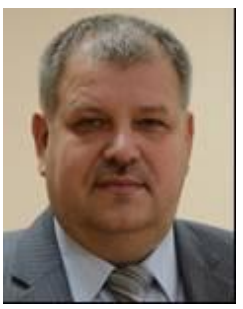

Kuzichkin Oleg Rudolfovich in 1984 received a radio engineer degree from the Vladimir Polytechnic Institute with a degree in Radio Engineering. In 1999 he successfully defended thesis on the topic: "The Monitoring System of Pulsed Geomagnetic Sources" at the Institute of Physics of the Earth, RAS and he was awarded the degree of Candidate of Physical and Mathematical Sciences. In 2009 for the work "Theoretical Foundations of Automated Electromagnetic Control of Geodynamic Objects" he was awarded the degree of Doctor of Technical Sciences. Currently he is a professor at the Department of Information and Robotic Systems at Belgorod State University. Fields of scientific interests: monitoring and diagnostics systems, radio engineering systems, geodynamic monitoring, measuring equipment, electromagnetic signals, information processing, expert systems, automated systems. E-mail: oldolkuz@y andex.ru.

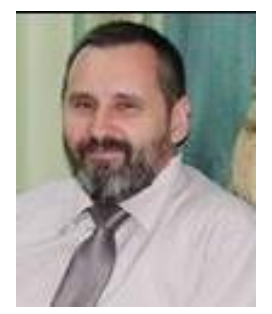

Eremenko Vladimir Tarasovich successfully defended his dissertation research and received a doctorate in technical sciences. Currently, he is the head of the Department of Information Security of the Federal State Budgetary Educational Institution of Higher Education "Ory ol State University named after I.S. Turgenev ", Russia. His research interests include information security and information protection, cryptographic methods of information protection, information confrontation in sociotechnical systems, information security management. Email: wladimir@orel.ru.

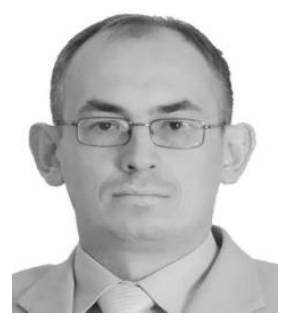

Loginov Ilya Valentinovich successfully defended his dissertation research and received a degree of candidate of technical sciences. Currently, he is a doctoral candidate in the Department of Information Security of the Oryol State University named after I.S. Turgenev ", Russia. His research interests include information security and information protection, cryptographic methods of information protection, information confrontation in sociotechnical systems, information security management. Email: loginov_iv@bk.ru. 


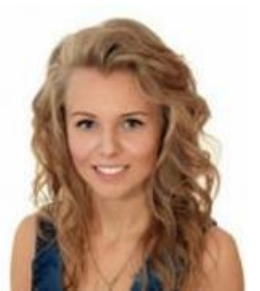

Grecheneva Anastasia Vladimirovna received a degree in "Devices and Methods of Quality Control and Diagnostics" at Vladimir State University, Russia, in 2015. In 2019, she defended her thesis for the degree of candidate of technical sciences $(\mathrm{PhD})$. Currently, she is an assistant professor at Vladimir State University, Russia. Her research interests include automated monitoring systems, geotechnical monitoring, control of geomechanical parameters, measurement methods and tools, and processing heterogeneous data. Email: nastena07_93@mail.ru.

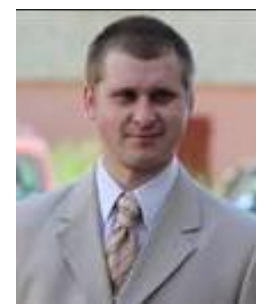

Eremenko Alexey Vladimirovich successfully defended his dissertation research and received a degree of candidate of technical sciences. Currently, he is a doctoral candidate in the Department of Information Security of the Oryol State University named after I.S. Turgenev ", Russia. His research interests include information security and information protection, cryptographic methods of information protection, information confrontation in sociotechnical systems, information security management. Email: kafedra.ib@mail.ru.

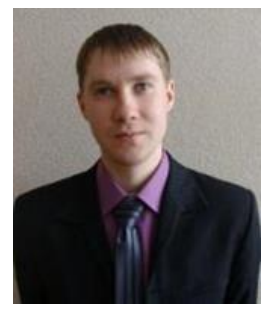

Dorofeev Nikolay Viktorovich received an engineering degree in Computer Engineering, Complexes, Systems and Networks at Vladimir State University, Russia, in 2006. He defended the dissertation of the candidate of technical sciences in the specialty "Instruments and methods for monitoring the environment, substances, materials and products" in 2010, the dissertation of the doctor of technical sciences in the specialty "System analysis, management and information processing" - in 2019. From 2012 to the present, he has been working as the head of the Department of Management and Control in Technical Systems, Vladimir State University, Russia. His research interests include monitoring systems, surface geody namics, risk assessment, forecasting. Email: dorofeevnv@yandex.ru. 